Abstracta Iranica Iranica

Revue bibliographique pour le domaine irano-aryen

Volume 32-33 | 2013

Comptes rendus des publications de 2009-2010

\title{
Gerd Gropp. Die Darstellung der 23 Volker auf den Reliefs des Apadana von Persepolis
}

\section{Barbara Kaim}

\section{(2) OpenEdition}

1 Journals

Édition électronique

URL : http://journals.openedition.org/abstractairanica/40498

DOI : 10.4000/abstractairanica.40498

ISSN : 1961-960X

\section{Éditeur :}

CNRS (UMR 7528 Mondes iraniens et indiens), Éditions de l'IFRI

\section{Édition imprimée}

Date de publication : 1 décembre 2013

ISSN : 0240-8910

\section{Référence électronique}

Barbara Kaim, «Gerd Gropp. Die Darstellung der 23 Volker auf den Reliefs des Apadana von Persepolis », Abstracta Iranica [En ligne], Volume 32-33 | 2013, document 158, mis en ligne le 01 juillet 2016, consulté le 03 octobre 2020. URL : http://journals.openedition.org/abstractairanica/40498; DOI : https://doi.org/10.4000/abstractairanica.40498

Ce document a été généré automatiquement le 3 octobre 2020.

Tous droits réservés 


\title{
Gerd Gropp. Die Darstellung der 23 Volker auf den Reliefs des Apadana von Persepolis
}

\author{
Barbara Kaim
}

\section{RÉFÉRENCE}

Gerd Gropp. « Die Darstellung der 23 Volker auf den Reliefs des Apadana von Persepolis ». Iranica Antiqua, 44, 2009, p. 283-359.

$1 \quad$ L'identification exacte des délégations représentées sur l'escalier est de l'Apadana est difficile en l'absence d'inscriptions. On se fonde généralement sur le costume des personnages, les objets et animaux amenés en tribut et aussi par comparaison avec d'autres représentations. Les délégués sont précédés par un huissier, vêtu à la perse, qui tient par la main le chef de la délégation et le mène devant le roi. Dans 9 cas, l'A. propose une identification différente de celle proposée récemment par $\mathrm{H}$. Koch, A. Tourovets ou G. Vittmann. Particulièrement intéressant est son identification des personnages qui mènent les délégations comme des satrapes de provinces.

\section{AUTEURS}

BARBARA KAIM

Université de Varsovie 